\title{
Sport and Physical Activities in the Czech Republic
}

\author{
Aleš Sekot \\ Masaryk University, Brno, Czech Republic
}

ABSTRACT

The situation on the field of physical/sportive activities in Czech Republic has been affected in the course of recent decades with fundamental political, economical and cultural changes of transforming society and general situation of workforce in context of sedentary society in particular. To contribute to increasing knowledge of the present-day position of sport in the Czech Republic means to search the relevant relations of municipalities and their policies to various levels of sport. To discuss the situation of sport includes describing the present position and role of sport activities in different societal and demografic parts of society too. From the perspective of the situation in sport delivery at the municipal level it must be borne in mind that there are diverse voluntary sports organizations in existence within the municipality, and, naturally, there is also the private sector. Underlying health determinants of a socioeconomic nature play a major role in causing vulnerability to health risks, including obesity as relevant negative reflection of passive way of life. Representative documents retrieved on national and school policies reflected by findings of the PREVOB Project confirmed mutually dependent and interconnected topical issues like nutrition policy and physical activity policy. The phenomenon of physical/sportive activity is connected with lifestyle behaviours. The most critical policy area on physical/sportive activity is the sole fact of sedentary nature of contemporary society: a very high level of prestige of sport and sportive activities in Czech society is incompatible with a very low level of practical regular physical or sport activities.

KEYWORDS sport, physical activity, life style, sport facilities, obesity, PREVOB project, major sport events; tourism destinations; sport marketing; qualitative local development; urban renewal; socio-cultural regeneration

\section{General situation}

The transformation from industrial to information society since the1960s and major advances in computer technology caused "the great wave of change". Significant changes in the composition of the workforce transformed the economic and the social roles of men and women, but also affected matters of health, attitudes to physical activities and sport. As a result of political and economic changes which occurred in the Czech Republic two decades ago, all areas of society started to be restructured. 
Naturally, this process also included public administration having responsibilities for many areas of the people's lives, including sport. This new way of "public matters provision" started at the beginning of the 1990s and culminated in the period of 2000-2002.

Together with this process, public administration at lower territorial levels started to constitute rapidly as a basis of democratic, and even more, civil society. The public policy process, therefore, became a subject of thorough investigation both for purely scientific reasons and also to provide theoretical knowledge as a support for the new processes in progress in the life of society. The area of sport, in relation to the public sector, has gone through great changes both in structural and process terms. The relations between the sphere of sport and the public sector are naturally mutually undergoing gradual changes.

The study of sport and public administration was approached also from the point of view of a relatively new scientific discipline, public policy theory, which studies diverse spheres of social life. The area of sport, however, has not been subject to this type of monitoring so far. To try to contribute to increasing the knowledge of the present-day position of sport in the Czech Republic it is useful to examine the relevant relations of municipalities and their policies to various levels of sport. The task is to explain how the situation has developed and which position sport has gained in the Czech public administration. And of course, to discuss the situation of sport, means to present the position and role of sport activities in different societal and demographic parts of society too.

With respect to the development of the Czech administration and sport during the past two decades, some ultimate facts must be stressed. This helps to understand the changes implemented and the reasons for their initiation. The year 1989 brought about the disintegration of a uniform voluntary sports organization, Czechoslovak Sport Association (ČSTV), which had also been responsible for sport within the whole of the former Czechoslovakia. This role of state supervision, however, was not newly delegated to any other body. The territorial structure of the state had changed (by dissolving regions) adopting the structural model: Czechoslovakia - Czech Republic and Slovak Republic counties - municipalities. In this structure, only municipalities had a self-governing status. Other levels represented state administration. The same structure persisted even after the split of Czechoslovakia into two separate states - the Czech Republic and the Slovak Republic.

With respect to sport, the year 1989 marked the disintegration of a uniform sports organization the Czechoslovak Sports Association. All sports associations, federations, and sports clubs, which had originally been its members controlled directly from the organization's centre, gained independence and became legal entities. Besides, large associations which had been dissolved after the Second World War (e. g. Sokol) and whose members with all their property had to merge with the Czechoslovak Sports Association at the end of the 1950s, renewed their activity. The voluntary sector started to follow the path towards a status that had existed for many years in Western European countries or in the former Czechoslovakia before 1948. The bodies in this sector became nongovernment, non-profit making, independent voluntary organizations with the status of legal entities.

The emancipation process of sports bodies at the beginning of the 1990s, however, also resulted in the necessity of tackling numerous problems related not only to these entities themselves, but to their relation to the all-society environment. At that time, there was no code specifying the role of the state and its components in relation to their support for sport, even though the Ministry for Education, Youth and Sport existed and was working. Still, however, advisory bodies as well as professional sections gradually started to work there, dealing with the national representation of sports, sport for all, research etc. Sport, as it was, was not regulated by any legal code, not even in relation to the municipalities. It was left to the municipalities themselves to decide whether to integrate the sport sector into their policies at all. 
At first, this situation was rather hopeless, but, in the course of time, many, mainly large municipalities, started to realize the importance of sport and searched for their own ways of supporting sport. The state did not join these initiatives until a change in political orientation from right-wing to left-wing social policy occurred in 1998. Preparatory works on government documents were started, dealing with the evaluation of the current situation and suggesting solutions for an all-national sport policy in the Czech Republic, an implementation of the system of national sports representation and support for talented youth, and the development of sport for all. The voluntary sector, which until then had stabilized and was looking for partnership and cooperation within its own ranks, also participated in these activities, taking on the role of a partner. The activities went in parallel with the preparations for the Czech Republic's accession to the EU and public administration restructuring. The most important reasons for this restructuring, given in a publication of the Ministry of the Interior elaborated in 1999, tried to get over high level of centralization and insufficient number of administration levels enabling implementation of subsidiarity principles (Slepičková, Staněk, 2007). But a continual deficiency of conceptual work on the field of balanced position of leisure and top levels of sport is still typical for relevant politics in the Czech Republic.

For the time being the administration of sport reflected Czech accession to the $E U$ and in such the state represents the highest level of public administration, regions are a combination of state and public administration, municipalities function as self-governing bodies with their own decisionmaking concerning their affairs being, of course, regulated by the current legislation. Subsidiarity principles in such a way affected the sport sector in the existence of voluntary (third) sector independent of highly segmented organizations. The voluntary sector is the sole owner of the largest Czech betting agency SAZKA. Sport is not incorporated in laws concerning regions and municipalities, but is only mentioned as one of the many areas that a municipality "may" deal with. The latter fact, in particular, initiated numerous research projects entitled Public Administration versus Sport (e.g. Slepičková 2000, 2001).

\section{Sport policy and its evaluation}

From the perspective of the situation in sport delivery at the municipal level it must be borne in mind that there are diverse voluntary sports organizations in existence within the municipality, and, naturally, there is also the private sector. The Czech Republic is also on the level of mass sport strongly influenced by the existence of a new development of the city structure with plenty of administrative buildings and shopping facilities, including fitness centres, cycle paths, roller-skating stadium, beach volleyball playing fields and golf courses. The authority for the implementation of the decisions with reference to sport policy and its evaluation is usually delegated to the municipal Department of Education and Culture with one specialized member of staff responsible for sport, and to the Department of the Environment, which is in charge of the reconstruction and maintenance of sports facilities owned by the municipality. In the area of support for sports organizations active on the administered territory, municipalities most often choose the possibility of awarding grants and the possibility of the utilization of school sports facilities. The conditions for gaining such support, however, show considerable differences. In some cases single sporting activities are supported, sometimes and somewhere open activities accessible for all, or only for members of individual sports associations. It is emphasised that the municipalities try to support all types of sporting activities.

The criteria for the selection of supported sports organizations or individual events are not firmly laid out, and it is mainly up to the members of the grant committee - which is also in charge of awarding grants in the sector of culture and other leisure time activities - which organizations or projects they will choose. The projects more likely to be supported are those that want to use the 
resources for purchasing material items rather than for the activity itself. The utilization of the resources spent is checked in a similar way: on the basis of annual accounts that the sports organizations winning the grants are obliged to submit to them. As far as the evaluation of the quality of these sports organizations' activity and their contribution to the inhabitants of the municipality is concerned, no rules or criteria have ever been set in any of the city quarters. The activity of sports organizations is assessed mostly only during public events held by them to which representatives of the local administration are invited as well. Their participation, however, is only voluntary.

In some city districts in Czech cities the strategy in relation to sports facilities focuses mainly on the reconstruction of those situated near primary schools, which are considered as the major basis for the development of sport. The utilization of these facilities applies the same rules set by the local administration, prefering long-term hiring contracts by local sports organizations. In multi-purpose facilities sport on currently unused fields is also allowed for other people not belonging to sports organizations. All this is subject to agreement with the facility caretakers, whose wages are partly paid from the school funds and partly subsidized by the municipality. The possibilities of sporting activities available for the city quarter inhabitants are repeatedly advertised on the Internet and in the local newsletter. The chief deficiency acutely felt by the local administrations in the Czech republic in general, is the absence of swimming pools whose construction is planned usually within three years.

Playgrounds of the city districts are usually administered by the Department of the Environment through an authorized member of staff, who monitors the condition of these playgrounds in terms of their physical condition and functionality. The city police is also engaged in the protection against vandalism, as a crucial problem of Czech society. The local administrations also rely on the people from the immediate vicinity and their interest in keeping the areas in good condition (reports of wrongdoing and vandalism) or make sports facilities situated near primary schools accessible for the public. Their regime is individual, fully under the authority of the school headmasters. Outdoor facilities are all provided to the public for free. In indoor spaces, the schools must respect the local administration regulations concerning the calculation of the prices for hire - their costs and resulting prices for hire calculated on their basis are submitted for approval by the Council on a half-year basis. The required personnel - school caretakers, keepers - are remunerated from the school budget. The municipality does not subsidize their wages in any way.

In general, the approaches of municipalities in the Czech republuic to sport show many differences. The causes of the identified differences and, in particular, of a totally different approach to policy making, therefore, must be sought elsewhere. In the different approaches to sport the political bias of elected and decision-making bodies of the municipality is reflected as well the degree of personal enthusiasm for sport of the persons who have decision-making powers in the municipality. Of importance is also the level and specialization of their professional qualifications and their willingness to take advantage of objective data (from research and surveys) on the situation in the municipality, i. e. also in the area of sport. The involvement of the voluntary sector as well has a significant share in the situation. It is evident in municipalities differing by their geographical position and appearance, by the number of inhabitants and their socio-economic characteristics and by economic development, thatsport policy-making is not yet a common standard. There are also a number of additional factors which are very likely to affect the approaches to solutions in the area of sport life(Slepičková, Staněk 2007).

To summarize the situation of sport versus local authorities in the Czech Republic, the financial limitations and political priorities play a very important role, as well as professional competence and personal preferences of particular councillors. The approach of the individual town areas to sport is very different and there are often original public policies in this field. A very diverse approach is also 
seen in the field of maintenance and development of the sports infrastructure and its utilization. In almost all of parts of the Czech Republic, great importance is placed on renovation of school facilities. However, the access of the general public to the sport facilities often collides with the clearly commercial use of the facilities (Staněk, Flemr 2007, 294-297).

\section{Some research data on physical and sportive activity of Czech population}

We live in the cultural setting adoring youth, beauty, healthy and sexy body and physical performance. Unfortunately, images of fit and healthy attractive personalities and widely circulated health messages have not translated effectively into increased physical activity for most Czech people. Findings from a number of large-scale surveys point to the aversion or the inability of most Czech people to participate in regular amounts of physical activity. Sportive activities are more or less rather the manifestation of a "contemporary" lifestyle, than an integral part of everyday life. It is for more and more financially prosperous people in good social position the expression of the prosperity and the ability to freely spend and choose independently their leisure.

People prefer, in general, passive forms of leisure, watching sport rather than doing sport. Overweight adults being deficient in good physical condition are putting themselves at risk of disease and disability. Medical expert predicted properly that through the decline in physical activity the current generation of Czech children will grow into the most obese generation of adults in Czech history: The sedentary living beset contemporary Czech society, identically to in the U.S. and plenty of European societies too. In such a situation we are more and more confronted with pressing questions: Why do people who know they should be more physically active still fail be so? What form do the obstacles to achieving a more physically active lifestyle take? And a very pragmatic question is brought up to date: Is it in sedentary postmodern virtually-oriented life possible to transform contemporary people into a more physical active society? What is the real prospect of our endeavour to create a social structure more conducive to a healthier society? Is it possible to overcome persistently questioned limitations found in many of the traditional approaches to promoting physical activity? Are we able to work effectively on the way of an innovative strategy to increase physical activity at home, at school, and within the community?

The existing whirlwind of changes associated with the way of life and standard of living regarding working activities, nutrition, housing, environment, transport, leisure, travelling etc. have without doubt had a strong impact on a physically active lifestyle. And we must face very a crucial fact: Some problems in this field are more or less under our control, but some barriers to improving active lifestyle are not. Anyway, enhancing the legitimacy of physical activity as a topic of systematic research would indeed be very gratifying.

The situation in the Czech Republic regarding obesity is reported as alarming: $21 \%$ of men and $31 \%$ of women are obese (obesity and overweight $=68 \%$ of women and $72 \%$ of men). $66 \%$ of men and $54 \%$ of women in the age group 20-65 are overweight or obese, while "only" $17 \%$ of men and 21 $\%$ of women are obese. In children the rates are $7 / 8 \%$ for overweight and $6 / 7 \%$ for obese (overweight and obesity in total 13-15\%). A specific phenomenon of Czech population is the obesity occurrence in all social groups with no strong differences in some social strata (Šeráková 2007, p. 814-815, Fořt 2004). Whatever results on obesity in the Czech Republic are given by the authors, all of them agree as will be discussed later - on the fact that the obesity prevalence is growing enormously, despite the fact that the situation need not be as critical as it is often presented in media and press.

Regarding systematic representative sociological research of physical activity - and consequently a social analysis of inactivity and patterns of sedentary living - in the Czech Republic 
we can summarize: Besides some partial surveys of leisure activities of young generation there exists some representative research of a position of sport and sportive activities of Czech population One very representative random sample of 952 respondents aged over 18 years of age was organized by Charles University in Prague. Research confirmed a very high level of prestige of sport and sportive activities in Czech society (Slepička, Slepičková 2002). But at the same time the generally known fact was confirmed that the significant part of population with its positive attitude to physical activities does not realize this in practical personal everyday life in the form of regular sport activities. Only one third of respondents declared regular sportive activity at least once a week, one fifth of respondents is involved in sport irregularly and by chance. Seventy percent of Czech people are not members of sports organizations. On the decline is also positive opinion stressing an importance of mass sportive activity. Presented research has not only been interested in the opinion of the Czech population on the role of sport for contemporary people, but has also searched for existing interests in alternative sports, prevailing barriers of active sporting, accessibility to sport facilities, level of passive and active interests regarding sport. A fundamental topic in the mentioned research, the general importance of sport and physical activities for the Czech population, is reflected in the following answers (Table 1):

Table 2. General importance of sport and physical activities for Czech population

\begin{tabular}{lr}
\hline Importance of sport and physical activities & $\mathbf{\%}$ \\
\hline Not important & 2,4 \\
Important only for someone & 17,5 \\
Important, particularly for youth & 21,6 \\
Important for all generations & 58,3 \\
No answer & 0,1 \\
\hline
\end{tabular}

A distribution of answers reflects a very high level of positive importance of sport for individuals and the society too: People are in the course of their life confronted with the rational evaluation of sport for practical life. The highest importance is connected with the positive contribution of sportive activities for the health, fitness, well-being, social prestige. Such an attitude reflects also the high value of acknowledgement and a credit of health for all generations of the population. At the same time the impact of sport as an indispensable factor of socialization is growing, notably as a form of meaningful pursuit of leisure.

A pivotal problem of opinions relating to desirable level of mass sport activities is reflected in this set of answers (Table 2):

Table 3. Desirable level of mass sport activities

\begin{tabular}{lr}
\hline Desirable level of mass sport activities & $\mathbf{\%}$ \\
\hline We need more active sport & 62,0 \\
Meeting the proper requirements & 25,0 \\
We have too much sport & 3,2 \\
No opinion & 9,1 \\
No answer & 0,1 \\
\hline
\end{tabular}

Also such a table reflects the existing discrepancy between positive attitudes to sport and the conviction to be more intensively involved in active sport (Slepička, Slepičková 2002, p.15).

Respondents offer very interesting data on the question: "What is the main reason for prevailing sport inactivity of today's people?" The presented structure of attitudes to sport activities reflects the given social and cultural situation in the Czech post-reformation setting: People are not consistent enough to overcome their laziness, are too busy, too involved in everyday economic problems, not properly appreciating and enjoying refreshing impact of regular physical activities compensating 
multi-faceted stress of societal life. But we also take into account the fact that people are prone to declare an absence of leisure for non-genuine reasons.

Table 3. Reasons of prevailing sport inactivity

\begin{tabular}{lrr}
\hline Reasons of prevailing sport inactivity & $\begin{array}{r}\text { Agreement } \\
\mathbf{\%}\end{array}$ & $\begin{array}{r}\text { Disagreement } \\
\mathbf{\%}\end{array}$ \\
\hline People are too lazy & 86,3 & 13,7 \\
People are too busy & 81,0 & 19,0 \\
People face the lack of sport facilities & 34,0 & 66,0 \\
Too expensive for most people & 52,0 & 48,0 \\
Absence of proper party or team & 38,0 & 62,0 \\
People have another cares & 83,0 & 17,0 \\
Absenting effective promotion & 37,0 & 63,0 \\
\hline
\end{tabular}

Regarding researching the problem of "an opinion to future development of mass sport", respondents declared:

Table 4. Reasons of prevailing sport inactivity

\begin{tabular}{lrrr}
\hline Future development of mass sport & $\begin{array}{r}\text { Yes } \\
\mathbf{\%}\end{array}$ & $\begin{array}{r}\text { No } \\
\mathbf{\%}\end{array}$ & $\begin{array}{r}\text { No opinion } \\
\mathbf{\%}\end{array}$ \\
\hline People will be more involved in sport activities & 36,6 & 29,1 & 34,1 \\
Stronger gap between top and mass sport & 70,4 & 9,9 & 19,4 \\
Increasing importance of sport as a medial show & 44,3 & 19,7 & 35,5 \\
Increasing costs for active sport & 88,4 & 2,8 & 8,3 \\
Some sports will be only for very rich people & 81,4 & 6,6 & 11,6 \\
\hline
\end{tabular}

Respondents declared widely prevailing sceptical opinions reflecting the existing process of growing disparity between top elite professional sport and mass recreational sport. Such a process also supports the consumerist nature of contemporary sport in general. The most frequent reasons for sporting activities of men is building up physical condition, body shape and societal prestige. Women are more sceptical in reference to their opportunity to practise recreational sport regularly: They complain of an absence of leisure, financial potential and organisational obstacles.

Research data relative to physical fitness demonstrate the following picture:

Table 5. Physical fitness

\begin{tabular}{lr}
\hline Physical fitness & $\mathbf{\%}$ \\
\hline I am in good physical condition & 27,7 \\
Generally good fitness & 41,7 \\
Not very good & 20,7 \\
I feel physically very bad & 12,9 \\
\hline
\end{tabular}

Relatively positive perception of physical condition of respondents is reflected in the declaration of frequency of sport activities:

Table 6. Frequency of sport activities

\begin{tabular}{lr}
\hline Physical fitness & $\mathbf{\%}$ \\
\hline Vigorously and regularly & 33,1 \\
Occasionally & 20,7 \\
Only in the past & 18,5 \\
Never, but I would like to & 5,6 \\
Never on principle & 22,1 \\
\hline
\end{tabular}


One third of respondents declares active sport activities at least once a week ( $37 \%$ of men, $29 \%$ of women). Women are doing sport activities less regularly $(22,7 \%)$ in relation to men $(14,6 \%)$. Women are also more frequently absolutely physically inactive than men.

The presented data reflects the growing tendency in the Czech population of passive attitudes to sport. Physical inactivity is justified by the absence of leisure, absence of meaningful motivation and an existence of health problems. $40 \%$ of the "programmatic physically inactive" acknowledge substantial aversion to physical activity, $28,5 \%$ declare health problems and $20 \%$ an absence of leisure. Only marginally is the absence of sport facilities and financial obstacles declared (Slepička, Slepičková 2002, p. 19-21).

Relevant recommendations regarding physical activities from the mentioned research emphasise: More opportunities for active sportive activities for older men and women; To prepare and to realize self-contained programs for active recreational sport for all groups of population; Within school teaching of physical education contribute to a long-life interest in active physical activities; Support in general walking as the most natural form of physical activity (Frömel, Bauman et al. 2006, p. 21).

In the Czech context it is necessary to mention that 2 hours of physical education per week for pupils and students is nowhere near enough. Also young people are recommended for active participation in tourism, recreation and sport, as the foundation of physical culture. Physical education in its humanistic version is understood as "an education of man for the care of the body".

Another representative research of 5825 respondents monitoring physical and sportive activities, "Physical activity of men and women 18 to 55 years old in the Czech Republic", reveals that men in all age categories exhibit more days of physical activity than women, and also decrease in frequency of general physical activity with age. Only in walking are the women of all age groups more active than men; in general an apparent decrease in walking in the course of ageing is evident. Sedentary way of life measured by time spent in sitting daily is more typical for women. It is concluded that the Czech population is not engaged in vigorous physical activity that promotes the development and maintenance of proper physical shape. To be engaged, preferably daily, in moderate physical activity for at least 30 minutes, is unfortunately only a recommended imperative, but not reality. A higher level of intensive and moderate physical activity for both men and women and a lower average period of sedentary time is recommended for the general Czech population (Frömel et al. 2004, p. 173).

From the perspective of leisure time activities it is evident that in the Czech Republic physical activities are much more important in the life of children and young people than in adults.

More boys than girls devote themselves to organized sports, even though in recent years the number of girls participating mainly in unorganized forms of physical activities has increased.

$42 \%$ of the boys and $34 \%$ of the girls are engaged in all the existing organized forms of sport. $30 \%$ of young people are interested in the subculture of "new sports" including adventure activities, which are becoming more popular than the traditional ones. But the high percentage of young people who do not practise any sport is alarming because of the prognosis of the possible appearance of health-risk factors. Participation in sport and physical activities according to gender, age and forms of sports shows that the Czech boys in all the observed age categories (9-24 years) participate in intensive and moderately intensive physical activity more days in the week than girls. These differences continue with increasing years of both gender. The average daily time for intensive physical activity is 51 minutes for boys and 33 minutes for girls. But no remarkable differences in socalled "walking days" between boys and girls were registered (Rychtecký 2007, p. 205). 
Frequency of participation of Czech males in competitive, organized, highly intensive sport is most evident in age group 9-11 years (27\%, strong enthusiasm regarding sport career), 12-13 year-old boys are most involved in intensive sports and physical activities, 9-11-year-olds are also nonparticipants in physical activities (32\%). Girls are most involved in intensive sporting activities in the age group 16-19 (32\%), the most passive attitudes regarding physical activities are typical for 9-11old girls (Rychecký 2007, p. 203-204) as a reflection of daily and weekly habitual order and social influences.

To participate in physical activity is a complex problem. One of the most important aspects of such phenomenon is the problem of motivation for a sport activity. An investigation of 956 Czech young people aged 15-24 with regard to their attitude to physical activities was recently conducted. The research covers both young people doing sport and those who are not doing sport. Main reasons for boys engaging in sport is sharing leisure with friends $(28,4 \%)$, to look good and to improve health, while for girls it is to look good (25\%), to share leisure with friends and to improve health (Sekot 2006, pp. 156-158). It is in the logic of the problem that aesthetic and health reasons for physical activities are more typical for girls and respondents who are not members of sport clubs.

Parallel research into health behaviour revealed the risk factors of young people's lifestyles. From the point of view of frequency of physical activities, only one third of Czech students spend 3 times a week with demanding physical activities, whilst on the contrary one fourth of respondents spend 10-14 hours daily sitting (28,6\% nursing school students) and the same proportion walks less than one hour a day $(29,3 \%$ grammar school students). "In general terms, the results confirm the present way of spending free time of young people - with the lack of motion and with a number of syndromes of an organism insufficiently loaded or overloaded in the wrong direction (pains in the back, joints etc.). Activities for health promotion have to be implemented informally, which means moving from filling in forms at schools to concrete health supporting activities: "These activities

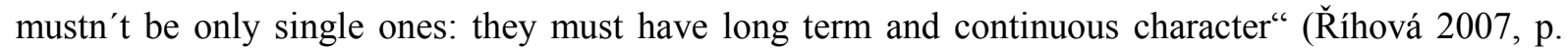
137-138).

In the Czech context a higher level of decentralization and competence transmission of regional autonomy is needed. To keep such a task, we need to monitor interest of physical activities in different age groups, evaluation of physical fitness level not only in children and youth, but also in adult population and elderly people. This means improving chances and amenities for regular lifelong physical activities, material outfit, preparation of specialists, realization of long-term education among coaches and instructors and fundament increasing of financial support for mass sport from the state. Sport for all must be an integral part of the future relation of sport to health, education and socialization. Recommendations to sport organizations for the systematic promotion of physical activities needs full support of local, regional and national public authorities:

1. To develop a membership strategy to include physically passive persons in sporting activities.

2. To specify the profile target of sport clubs with accordance to focus on elite and competitive sport or recreational leisure sport activities.

3. To improve coach and trainer standards of an inclusive social and pedagogical climate.

4. To stress natural outdoor activities as grassroots centres for mass involvement in physical activities.

5. To ensure and to enable high educational and pedagogical standards of voluntary and (semi)professional staff in sport clubs. 
Although the prospects for revitalization of physically active society are questionable, we are obliged to change or modify a long standing resistance to exercise among our contemporaries. Post industrial (or) post-modern society characterized in involvement in a momentary short term experience, refusing traditional and long term values, is not good place or cultural context for a transformation to physical activity both at the societal and individual level. Such a transformation will be filled with false stars and obstacles, facing innumerable barriers. These barriers (except general one's inborn individual laziness and indolence) range from political and legislative opposition to the struggle for limited resources with other health concerns and media indifference to social explanations for our physical activity problems. Public-policy makers have not paid sufficient attention to public and health preventive medicine and healthy lifestyles. We live in a situation when most people agree that healthy lifestyles are a fundamental good for individuals and society. But the sedentary lifestyle, imposes various other subjects, costs and negative impacts also on people not themselves directly engaged in health-risking behaviours: Strong smoking and sedentary lifestyle of one member of the family could induce emotional stress for the rest of the family or may cause individual financial hardship related to loss of job or overwhelming medical costs. From the strictly economic point of view, sedentary lifestyles costs billions in healthcare and lost wages are contributing to economic drain on society as a whole. Another problem is related to the question of how far the national physical activity agenda can go in regulating personal behaviours: People do not want to be told what to eat, what to drink, and how much to exercise. Anyway, our chance to achieve a physical active society could be improved if we can overcome the challenges of truly healthy lifestyles available to all members of society, or at least for most parts of society.

\section{Urbanisation versus sport facilities}

The phenomenon of the physical and sport is closely related to urbanisation of sports facilities. In such a context it is useful to describe and analyse the most important milestones in the history of city-planning (urbanisation) in the area of sport facilities. Compared with the development of sport facilities of ancient times, the current comparable status seems to be rather negative. Furthermore, it is the paradox that low quality of urban-planning nowadays is reflected particularly in the suburban areas of Prague, whereas the public infrastructure (sport facilities included) does not reach a sufficient level. The rapid housing and industrial development especially in these parts of the city has unfortunately overtaken the local development framework, which is resulting in numerous urban-architectural and moreover sociological issues. Sport facilities planning, creating, developing and managing should be considered to be one of the strategic points in public administration on both the local and state level (Flemr 2007, pp. 93-105).

The very beginning of the modern sport facilities - formerly the playgrounds - is illustrated from the $18^{\text {th }}$ century as a consequence of the sport movement in England as well as the philanthropic movement in Germany. The simple separate playgrounds had been constructed in the context of growing spectator popularity of sport with regard for spectators, mostly for tennis and athletic and football stadiums. In Scandinavia indoor facilities had also been constructed since the beginning of the $18^{\text {th }}$ century. In the Czech background the first real gymnasium was launched in 1862 - Malypetr gymnasium, used with the Gymnastic Association of Prague. The last decade of the $19^{\text {th }}$ century brought strong practical incentives for school and public gymnasiums and subsequent sports facilities. At the beginning of the last decade of the $19^{\text {th }}$ century about 500 tennis courts were in operation in Czech countries. In the late $19^{\text {th }}$ and early $20^{\text {th }}$ centuries there was improved public mass interest in football and biking. Strong incentives for mass sporting activities were connected with the existence of the Sokol movement and the modern Olympic Games in 1896. 
The formation of an independent Czech Republic in 1918 entailed a strong impulse for building new sports facilities, notably those for ice hockey, football and gymnastics. An advisory committee for physical education was established in 1920, coordinating a conception of building new sports facilities, for youth in particular. Despite this endeavour, only $11,3 \%$ of elementary schools had their own gymnasium, 45,3\% exercise grounds or a courtyard. There was a better situation in secondary and high schools: $75 \%$ of them possessed a gymnasium (Flemr 2007, p. 95).

Socialist planning emphasised unified physical education and sport. During the late 1940s in the Czech Republic there were 1250 centrally operated gymnasiums, only four indoor 25 -meter swimming pools and one indoor ice hockey stadium. The growing emphasis on mass physical educational activities and sport brought about the construction of new sports complexes, some of them of very low technological quality. The Czech association of physical education since its founding in 1957 had been a chief agent for purposefulness of sports facilities. Until the early 1990s the theoretical urbanistic value of sports sites for one single inhabitant was $17 \mathrm{~m}^{2}$, nowadays the exercise site for one inhabitant is $5,09 \mathrm{~m}^{2}\left(1,99 \mathrm{~m}^{2}\right.$ for an organized sport, $1,79 \mathrm{~m}^{2}$ for a school physical education, 1,31 for unorganized sport), and the usable exercise site for one inhabitant is $7,24 \mathrm{~m}^{2}\left(2,88 \mathrm{~m}^{2}\right.$ for organized sport, 2,22 for school physical education, 2,14 for unorganized sport). Municipal sportive institutions are basically non- profit-making - no wonder that investors prefer to invest in commercial sportive facilities. This is reflected in the rather neglected situation of mass recreational and leisure time sport activities in the Czech Republic.

It is generally emphasised, and in the Czech context too, that the municipal policy must support active lifestyle of very colourful broad spectrum of the population. Such an objective is strongly stressed, mostly after 1989 during the process of European Union integration. Within the European priorities health issues and active lifestyle of citizens are included. Sport and physical activities represent significant features of those priorities. In such a context, the relevant terminology of this area is elucidated, the terms such as active lifestyle and public policy are defined. In summarizing the current situation in the Czech cities the imperative of an active way of municipal sport policy is underlined. But in fact unfortunately rather closely reactive policy has been implemented in the Czech context: Mostly existing problems are solved, but future complex interventional programmes are rather ignored. The voluntary field must compensate for public boards and managements (Slepičková, Staněk 2007, Staněk, Flemr 2007).

Sport and physical activities in the Czech Republic are also supported in the form of various subsidies. But given the ongoing decentralization policy of the state, numerous problems of given forms of the support of sport and physical activities are not completely solved. So we face some features of the absence of coordinated policy of an effective support of sport damaged by ineffective financing, a high level of political and lobby decisions. Since 2000, the distribution of subsidies for sport and physical education has been directed to municipalities that invest into development of sport and leisure time infrastructure aimed at the growth of the local economy, tourism and recreation. The national support of sport is, nowadays, divided into the support of top sports, performance sports and new waves in sports (e.g. sports for everyone - for all), sports for school, which are then on the regional level (and by the various sport organizations) subsidized from other sources and, moreover, not co-ordinated. The correrspondence in subsidy policies of all the subvention levels, i.e. national and regional governments and sport organizations, is thus strongly required (Hobza, Cikl 2007, p. 79-80). A scheme of priorities in the different levels is proposed to avoid financially unclear and duplicate sources flowing to selected areas. Due to their multi-source financing, sports and physical education are then at the risk of accumulation of sources in certain areas and a lack of sources in others that are not politically supported, but still of high social importance. 


\section{Socioeconomic indicators of physical activity}

Underlying health determinants of a socioeconomic nature play a major role in causing vulnerability to health risks, including obesity. Indeed, a social gradient in obesity has been demonstrated with individuals in lower socioeconomic groups (lower incomes or lower levels of education, or both) having a higher risk of being obese and thus of suffering from obesity-related diseases. The reasons why these inequalities have arisen and persist include the constraints imposed by low income and educational achievement on food choices, opportunities for recreational exercise, and differential absorption of health promotion messages.

People prefer, in general, passive form of leisure, watching sport rather then doing sport. Overweight adults being deficient in good physical condition are putting themselves at risk of disease and disability.

Hlúbik_et al, carried out an investigation on obesity in the Czech Republic in the year 2000. The study monitored 933 volunteers, of both sexes and with an age range of 19-60 years. Anthropometric parameters such as weight, height, skin fold thickness and abdomen circumference were measured. BMI and fat tissue percentage were calculated on the basis of the data gathered. The authors detected overweight in $67,5 \%$ of monitored men, and obesity in $17,0 \%$ of them. $50,0 \%$ of women were overweight, while obesity was detected in $18,9 \%$ of them. Waist circumference exceeding $102 \mathrm{~cm}$ was measured in $41,2 \%$ of men and waist circumference exceeding $88 \mathrm{~cm}$ in $41,7 \%$ of monitored women (Hlúbik 2000).

Physical activity is a complex behaviour. Any activity can be described in terms such as intensity, frequency and duration, and these dimensions must be considered. An assessment methodology should also consider inactivity, such as time spent sitting. Physical activity can be related to work, transportation, home and leisure time. The activities at either of these domains may have specific health consequences, and advanced monitoring should also consider these.

The latest representative sociological research into the physical activity of the Czech population was conducted during the 2003-2004 period. The aim of the research "The intensity and the volume of physical activity of the population aged 15-69 in the Czech Republic" was to provide relevant data concerning physical activity of the inhabitants of the Czech Republic that are comparable to characteristics common in other countries. This will provide ground for further research in the future and allow evaluation of the conditions and trends in active lifestyle more objectively. Respondents were selected as a systematic random sample of males $(n=5186)$ and females $(n=5614)$ aged 15-69. The level of physical activity was assessed using the short version of the International Physical Activity Questionnaire that is used in worldwide research.

In reference to the results: There is a decline in the number of days in a week when both older men and older women engage in vigorous physical activity, and there is a decline in how much time they spend doing this kind of activity. As for moderate physical activity and walking in relation to age and gender, there are no significant differences in most characteristics: The overall extent of physical activity of men (Mdn = 4,776 MET-min.week) is higher than for women (Mdn = 3,705 METmin.week). Only 39,69\% of the inhabitants of the Czech Republic meet the recommendations of the "Healthy People 2010" program. Walking is the leading physical activity of the Czech inhabitants. Males and females' participation in an organized physical activity decreases significantly with age (Frömel K., Bauman S. et al. 2006). To present the most important results of the above-mentioned research means it is possible to conclude:

1. With growing age of population (men and women too) the number of week days and volume of time devoted to physical activity decreases. 
2. Men in general are more involved in physical activities compared women.

3. With growing age the existing differences in intensity of physical activity between men and women decrease.

4. Medium level of physical activity and walking is distributed in age groups and gender groups relatively evenly.

5. Walking is the most frequent form of physical activity in the Czech population.

6. Regular monitoring of level and tendencies of physical activity of the population is an integral part of monitoring of health situation and lifestyle of the population.

Relevant recommendations regarding physical activities from the mentioned research emphasise:

1. More opportunities for active sporting activities for the older population of men and women.

2. To prepare and to realize self-contained programs for active recreational sport for all groups of the population.

3. Within school teaching of physical education contribute to long-life interest in active physical activities.

4. Support in general walking as a most natural form of physical activity (Frömel Bauman et al. 2006).

The phenomenon of obesity in the context of physical activity is strongly connected with the area of teaching of physical education on a given level of school. One of the most important roles for acquiring proper habits and patterns regarding regular lifelong physical sporting activity is played by primary and secondary schools. A research sample of 153 11-15 years old rural Czech pupils revealed $20,0 \%$ overweight boys and 9,6 \% overweight girls, $2,9 \%$ obese boys and 1,2 \% obese girls. On the contrary, $14,3 \%$ of boys and $21,7 \%$ of girls were under the commensurate weight (Rýgl 2006). Most respondents are interested in collective sporting activities (e. g. ski training, biking, boating). The most popular sports games for 12-year-old girls are ball games, pig-in-the middle, rugby, floorball, volleyball and baseball. Boys of the same age prefer floorball, football, rugby, handball and baseball. Overall results refer to a high level of popularity of physical education comprehended mostly as a explicitly attractive activity. Research in such context stresses a necessity to improve salubrious and emotively experienced aspects of physical education to improve high competence of kinetic physical activities for lifelong body and health care. In the Czech context it is necessary to mention repeatedly that 2 hours of physical education per week for pupils and student is nowhere near enough.

\section{Physical activity versus obesity with the perspective of PREVOB Project}

In order to assess the extent of development and implementation of selected policy areas on dietary intake, physical activity level and obesity throughout Europe, health researchers, physical activity managers, and decision-makers are searching for a common methodology. Between the Autumn of 2008 and the Spring of 2009, thanks to support of the WHO a pilot project was tested in five European countries chosen to represent five sub-regions of Europe, namely Bosnia and Herzegovina, the Czech Republic, France, Latvia and Turkey. Moreover, sub-regional working groups made up of stakeholders and experts have been set up to review the results of the pilot tests and discuss the relevance and applicability of the Policy Analysis tool within their sub-region. 
The first conclusion regarding general results of the pilot test in terms of policy in reference to complex documents on obesity, nutrition and physical activity reflecting the situation in the Czech Republic in general is that they ignore in some respects the phenomenon of inequality. Physical activity policy documents (national and state ones) abstract away from problems of obesity and only marginally refer to the phenomenon of inequality of participation in regular physical/sportive activities. As a strategy government/ministry documents promote general education of a healthy lifestyle in schools and support construction and maintenance of sporting facilities in the Czech Republic in order to enable regular physical activity for the handicapped too.

Representative documents retrieved on national and school policies reflect mutually dependent and interconnected topical issues like nutrition policy, physical activity policy, compulsory nutrition education, free or subsidised school meals, fruit or vegetables, marketing restrictions with regards to foods high in fat, sugar, or salt, restrictions on what items can be sold from vending machine in schools, free available drinking water in schools, compulsory physical activity education, special physical education for disadvantaged groups or girls, promoting safe 'walk to school' routes.

Applicability, relevance and usefulness of the tool for Central Europe is from the perspective of the policy checklist partly limited by the fact that there are only narrow opportunities available to obtain and thereafter to analyze relevant documents that are mostly very formal and lack the criteria of personal or institutional responsibility for realization of declared intentions.

Official documents on physical/sport activity are not complex: They are rather declaratory with no effective means for monitoring and effective realization of the main objectives and do not directly support the mass form of generally accessible physical/sportive activities.

Recommendations for changes to the tool are extrapolated from the prevailing formal nature of processed documents and information. Policy analysis also needs in some specific situations an individual interview with relevant persons responsible for supervision and inspection of fundamental intentions and time-limited tasks of constituent parts of policy tools with regard to nutrition and physical activity.

Perspective of applicability of the community questionnaire reflects the fact that most hypotheses in this context were not confirmed. As a consequence we conclude:

1. To respect the fact that the number (and respectively the quality) of neighbourhoods is reflected on concentration of cycle paths only indirectly or vicariously: Cycle paths are intended and constructed primarily with respect to suitable natural and terrain preconditions with no direct and verifiable relation to cultural and economical nature of given neighbourhoods: As a practical consequence the existence of cycle lanes does not vary by social setting and "visibly and tangibly" higher quality of cycle lines passing through wealthier neighbourhoods is not supposed.

2. With reference to the existence and quality of public open spaces and playgrounds, in the context of rejected reasonably sounding hypothesis on higher quality in wealthier neighbourhoods, the existing general high level of vandalism and culturally non-conclusive distinctions are to be reminded in the context of different social and economical strata in most "post-communist countries".

3. Existence and quality of public transport stops reflects the quality of public transport in general and the relevant local social, cultural and economic situations too. But it must be said that the Czech Republic (as well as sub-regions of Central Europe) is very traditionally oriented towards an efficient public transport system fitted with modern transport vehicles and a compactly distributed network of public transport stops. But in general, the quality of 
transport stops is first and foremost given by the nature of passengers (mostly lower social strata) with no direct relations to nature of the relevant neighbourhoods.

4. Frequency of traffic volume is an outcome of few factors or agents: The phenomenon of traffic volume is multi-dimensional one and as such is not linearly shaped with an immediate social and cultural setting.

5. Pavements are public property determined from the perspective of existence and quality with plurality of economic, technological, social and cultural circumstances, not always having exact qualitative and quantitative outcomes.

6. It is useful to respect the fact that in the territory of a "post-communist country" (countries) the built environment is not socially and culturally structured enough to reflect visible and tangible attributes of sociologically structured levels of neighbourhoods.

The starting point of Czech participation in the PREVOB project was fundamental information on obesity in the Czech population: $52 \%$ of the Czech population exceed accepted parameters. There appears to be a north-south gradient in the prevalence of obesity, with higher BMI reported in towns of the north (mostly inhabited by socially disadvantaged populations) of the Czech Republic. Previous epidemiologic studies showed that at least $52 \%$ of the Czech population would like to maintain their weight under normal limits and $42 \%$ (including $50 \%$ of women) would like to reduce it,. Twentythree percent of the population affected by obesity are completely satisfied with their own weight (Czech Society for the Study of Obesity).

\section{PREVOB - physical activity versus built environment}

The above-mentioned PREVOB Project summarized some important data regarding built environment in the context of chances and limitations for mass physical/sports activities. So we can conclude:

1. Active participants and practical users of cycle lanes. Most of them are recruited from social strata characterized by an interest in healthy and active lifestyle incorporating regular leisure physical / sport activities. It would be very useful to identify a more detailed structure of cycle lanes with respect to intensity of physical/sportive activities. It is supposed that at least two fundamentals categories of cycle lane users exist:

a. regular users involved in periodical physical/sportive activities as a part of leisure in the context of everyday life.

b. occasional or provisionally "would-be sportsmen" involved in cycling mostly as a part of personal image practising cycling predominantly as a social activity without deeper rooting in value orientation containing regular physical/sportive activities as an integral part of everyday life.

Specific feature of the "cycle lane scene" in the Czech Republic calls attention to the growing presence of roller skaters, which - sometimes and in some routes - exceed half of given participants. This reflects on the one hand the high dynamics of the popularity of roller-skating and on the other hand the poor level of official and legal regulation or conception of "game rules" of cycle lanes. Unfortunately - with all respective negative impacts for participants - collisions, injuries, interpersonal conflicts ensue.

Another typical aspect of monitored cycle paths is rather their "leisure" nature. Cycle paths are mostly located in suburban or outskirt areas rather connecting recreational points than local points of everyday practical activities. As a consequence it is not in practice possible to use cycle paths for 
travel to work, to deal with civic affairs or with shopping. Cycle paths are mostly used for one-sided leisure activities. Good physical and psychological shape, well-being or personal image are most frequent reasons for being part of the cycle lane scene; practical means of everyday transport are only a marginal motive of mass cycling in the Czech Republic.

2. Public open spaces as a part of built environment are - from the perspective of their quantity as well as from the point of view of their quality - dependent on the fundamental character of given settings: Social, cultural and economical features of selected areas play a very important role and are also a significant precondition for the appearance of public parks and public playgrounds. Wealthier neighbourhoods provide more parks and playgrounds than socially, culturally and economically less booming, poor, disadvantaged or neglected boroughs (or even ghettos). Most striking dividing lines or contrasts are visible and tangible between ethnical ghettos (gypsy ones) on the one side and prestigious boroughs on the other side. In reference to public parks their occurrence as well as their quality (maintenance, neatness, service, safety) is incomparably higher in healthy boroughs than the analogous situation in poor neighbourhoods. In given situation another feature also exists: In top prestigious "high society" neighbourhoods, inhabited by people living in private family houses, villas or residences, the existing public parks are not so well visited or popular - local people prefer to stay in the luxury of their houses and gardens or to visit "specific" leisure and recreational facilities in different or distant places. Most popular are public parks in well-sustained "middle class" neighbourhoods provided in most cases with playgrounds for children. On the contrary, public parks in socially neglected parts of the city are rather small, badly maintained, dirty and insecure. Common problems of most public parks in all neighbourhoods are dog excrement and vandalism.

3. Playgrounds - form the side of their existence and their quality - vary as a matter of the principle - in accordance with the above-mentioned situation in public parks: higher quality exists in wealthier neighbourhoods; neglected and miserably provided in poor neighbourhoods. A specific aspect of the latter mentioned ones is the high level of vandalism. In some public playgrounds interested people are allowed to enter and use public playgrounds only in the presence of a commissioned person delegated by the local municipality! Another negative aspect of monitored public playgrounds is the absence of publicly available sporting and fitness equipment and facilities: presumably as a consequence of apprehension about vandalism. Public playgrounds are in fact on the defensive against the growing occurrence of commercial fitness centres. Such a situation reflects the deepening gap between different social stratums (and quintiles) with negative impacts on quality of life and structure of leisure of socially lower categories. The striking existence of vandalism as well as diffusion of lower social strata into higher quality public parks and playgrounds result in generally poor quality public open spaces in the researched localities - public parks and public playgrounds - and as a consequence rejection of the above-mentioned hypothesis.

4. Existence and quality of public transport stops reflects the quality of public transport in general and the relevant local social, cultural and economic situations too. It is not primarily the very existence of public transport stops, but their quality, reflecting the nature of given neighbourhoods. Quality, ergo the comfort, cosiness, neatness, non-desolation, and safety of public transport stops are supposed to be higher in healthier, better sustained and more secure neighbourhoods: Transport stops are secure shelters for passengers waiting for their bus, trolley bus or tram. Smoking is strictly forbidden on the tram platforms and transport stops. Sometimes, and mostly in the centre of the city, the welcomed appeal to care for health and 
fight against obesity is placed in the transport stops: "Presently the best way to improve your shape is to go to the next transport stop by walking".

The quality (but not directly the existence) of public transport stops in socially disadvantaged city districts is mostly decreasing in quality and with regard to comfort and security as a consequence of vandalism, deficient maintenance and the destructive presence of local youth gangs and socially nonadaptable individuals. Local youth also use (misuse) public indoor or roofed transport stops as a place for coming together or as a shelter in situation of bad weather. But in general, the quality of transport stops is first and foremost given by the nature of passengers (mostly lower social strata) with no direct relations to nature of the relevant neighbourhoods.

5. Frequency of traffic volume above all reflects the dynamic factor of general possession of private and business cars in the Czech Republic and the relative mass use of cars for everyday transport to work and for shopping. Suburban areas are strongly affected by truck transport and commuters, housing estates are affected by mass lodging typical for blocks of council houses are mostly in the vicinity of busy highways and supermarkets. On the contrary, housing estates of higher social class are mostly far - and detached - from busy and noisy roads, factories, business points and hypermarkets. The sparse population in private family house neighbourhoods benefit in many respect from low and quiet traffic volume, whilst the high concentration of population using the cars and traffic transport in socially low-grade housing estates and in the centre of the city is affected by busy noisy and polluting transport and traffic volume. But it must be taken into account that the phenomenon of traffic volume is multidimensional and as such is not linearly shaped by immediate social cultural settings.

6. The quality, durability and very existence of marked road crossings reflect in complexity the nature of the relevant built environment. The quality of road crossing reflects the quality of neighbourhoods: in general maintenance of all public places and buildings, the roads and their marking - so very important for transport security - in particular. Road marking is in disadvantaged housing estates also mostly emasculated via bad road maintenance of dirty shattered and pot-holed roads.

7. Pavements are an integral part of the built environment and as such they reflect the quality of relevant neighbourhoods. Pavements play an important role not only as a reflection of general quality of given public place, but they are also important for personal security of local inhabitants and walkers too. Pavements reflect quality, aesthetics and security of the built environment: Pavements are a visible and tangible demonstration of the level of built environment and relevant quality of life. Perfectly privately and municipally maintained pavements in family houses and mansions areas are strongly dissimilar to neglected, shabby and broken pavements used and occupied by parked cars and soiled with litter, cigarette butts and old dirt. But simultaneously pavements are public property determined from the perspective of existence and quality with plurality of economic, technological, social and cultural circumstances having not always exact qualitative and quantitative outcomes.

8. It is more than evident that built environment plays a very important and growing role in quality and attractiveness of neighbourhoods. Having or not having a "good neighbourhood" is a fact gaining strength in the post-communist Czech Republic too: The growing social and economic differences in Czech society increase the aspect of social inclusion and exclusion and having a "good address or bad address" is an important attribute for attractiveness/unattractiveness of built environment and usually plays more of a role in personal decision-making processes than simply the quality and aesthetic attractiveness of a given apartment or house. This is a factor in the level of prestige of a "private address" as well 
as a "business address". Despite the last decade of "unrestrained capitalism", more attention and more emphasis is currently being oriented not only at the level of attractiveness of new houses but the quality of the wider built environment - living conditions, quality of urbanism, stillness, transport accessibility, security, social structure, existence of schools, public facilities, shopping opportunities, level of air pollution, contact with nature and existence of sports facilities. But it must be remembered that the built environment in a given territory is not socially and culturally structured enough to reflect visible and tangible attributes of sociologically structured levels of neighbourhoods.

The most critical policy area of physical/sporting activity is the sole fact of the sedentary nature of contemporary society. It is evidently openly bitterly featured that a sedentary lifestyle develops as the result of a socialization process towards the physical inactivity developed in youth and continued into adulthood. Social analysis of inactivity and patterns of sedentary living conclude that in the Czech Republic there are, in summary, very high levels of prestige of sport and sporting activities in Czech society. But at the same time the generally known fact was confirmed that the significant part of population does not translate its positive attitude to physical sporting activities into practical personal everyday life in the form of regular physical or sport activities. People in the Czech Republic are in many respects permeated with the busy capitalist rhythm of "post-transformed society" oriented onesidedly at performance, success, popularity, money and societal admiration. In such a millieu endangered and problematic groups of the population are the busy, stressed, top businessmen, managers and "workaholics" feeling the lack of leisure time and the long car journeys, as well as socially deprived groups such as jobless people or ethnic minorities (mostly Gypsies) lacking proper value orientation accenting a healthy and sustainable style of life absorbing healthy dietary habits, regular intentional physical exercising, sportive and outdoor activities (Slepičková, Flemr eds. 2007).

\section{General conclusions relating to physical activity versus obesity}

- Obesity is a global public health problem. This epidemic is reversible.

- People's energy intake must exceed their energy expenditure over a prolonged period of time for them to become obese.

- Within most countries physical activity levels were lower and television viewing times were higher in overweight youths compared to those of normal weight. Increasing physical activity participation and decreasing television viewing should be the focus of strategies aimed at preventing and treating overweight and obesity in youth.

- We have to improve the understanding direct and indirect determinants of obesity, particularly as regards nutrition and physical activity in different age groups, as well as inequalities in obesity in the EU Member States.

- It will be important to enhance the understanding of the existing public health policy environment with regards to nutrition, physical activity, obesity with respect to relevant regulations in the EU.

- It is a priority to develop and pilot suitable flexible tools that will enable public health researchers and decision-makers to assess the potential impacts of proposed policies on dietary intake, physical activity level and obesity throughout Europe using a common methodology, and to assess the potential effects on the distribution of those impacts within the population (that is, issues of equity and impact on specific vulnerable groups). 
- It will be advisable for the governmental institutions to search for real opportunities for active sportive activities for older population of men and women.

- It will be necessary to test relevant situations in self-contained programs for active recreational sport for all groups of population.

- Real chances of school teaching of physical education need to be found to contribute to longlife interest in active physical activities.

- Most of our daily living environments such as transport, housing, employment, schools and leisure, are some of the causes that population are becoming less active. This physical inactivity has an alarming trend causing not only obesity but other associated health problems.

- Both children and adults of lower socioeconomic groups are found to be less physically active than those of higher socioeconomic status.

- Special attention has to be focused on vulnerable groups such as children, whose inexperience or credulity should not be exploited by commercial activities.

- A high level of political will and leadership are required to achieve a decrease in obesity prevalence.

- All relevant state sectors and levels should play a role.

- Civil society can support the policy response.

- The media have an important responsibility, preventing obesity and supporting healthy lifestyles.

\section{General conclusions on improving level of physical activities}

To discuss a phenomenon of physical activity means to mention also the changing nature of lifestyles and leisure time activities that have adopted new forms, contents and meanings. The world of sport and physical activities is also changing all the time, as can be seen in numerous new sport disciplines and activities which are be chosen by a growing number of people. It could be expected that these changes would affect also the socialisation situations and environments of physical activity.

The Czech situation must be prepared for the specific situation of ethnic minorities (mostly Romany populations) reflected on the level of their attitude to physical and sporting activity too. In traditional Romany culture the positive attitude to sport is derived from relevant value attitudes of the majority of society. Mostly the young generation of this minority appreciate sport in a positive way, thanks to peers and school education. Despite such a positive tendency only 14 per cent of gypsy youth are involved in regular sporting activities - mostly in football, jogging, biking, swimming and dancing (Hastrmanová, Houdek 2007). Also the 9-11-yearold pupils of practical elementary schools are not properly and proportionally involved in extracurricular movement activities. Just 19 per cent of them participate in organized physical activities, compared with 55 per cent of children from ordinary elementary schools.

The presented structure of attitudes to sport activities reflects the given social and cultural situation in the post-reformation Czech setting: People are not consistent enough to overcome their laziness, are far too busy, too involved in everyday economic problems, not properly appreciative of and enjoying the refreshing impact of regular physical activities compensating the multi-faceted stress of societal life. But we also take into account the fact, that people are prone to declare an absence of leisure for non-genuine reasons (Slepička, Slepičková 2002). 
The presented data reflect the growing tendency of passive attitudes to sport in the Czech population. Physical inactivity is justified by the absence of leisure, absence of meaningful motivation and an existence of health problems. $40 \%$ of the "programmatically physically inactive" acknowledge a substantial aversion to physical activity; $28.5 \%$ declare health problems and $20 \%$ an absence of leisure. Only a marginal share declare an absence of sports facilities and financial obstacles (Slepička, Slepičková 2002).

To present the most important results and information on tendencies in the field of physical activities means to conclude that with growing age (both for men and women) the number of weekdays and volume of time devoted to physical activity deceases. Men in general are more involved in physical activities compared to women and active transport (walking, cycling) is a very effective way of mass physical/sportive activity. There are relevant recommendations regarding physical activities which emphasise more opportunities for active sporting activities for the older population of men and women and for the overall population with respect to support via teaching of physical education for a life-long interest in active sport.

Nowadays physical education is defined as the process aiming at preparation of children and young people for participation in physical culture (tourism, recreation, sport). It is also understood as the foundation of physical culture. Physical education in its humanistic version is understood as "an education of man for the care of the body". Humanistic aspects relating to physical education stress intentional activity aiming at forming positive attitudes towards the body, familiarizing a person with the world of physical culture consisting in shaping attitudes towards the body and the values of physical culture, an education for the values of the healthy body, an education of the personality for the care of the body., preparing children and young people for taking responsibility for health, fitness and the beauty of the body after competing education.

Social environments consist of the non-physical products of human interaction, which include the ideas and values shared by members of a particular group as well as those who come together to participate. Social connectedness plays an indispensable role in matters of good health: Meaningful social relations contribute to a harmonious personality and in consequence also enhance positive health behaviour and physical shape. In several medical studies, social connection has been associated with improvement in behavioural health factors, such as quitting smoking, compliance with medical regimes, control of diet, and physical activity. The synergistic roles of physical and social environments affect participation in physical activity. Resulting behavioural settings can promote physical activity when they provide the physical space (e.g., sports facilities, health clubs, bicycle paths, swimming pools) along with the social resources that we draw upon to interact with others in community-policing programs.

The phenomenon of physical/sportive activity is a multi-faceted phenomenon connected with the concept of a healthy lifestyle. Lifestyle behaviours in general are significantly determined by social status, by professional position, by amounts of money and property ownership. Those who have the means may choose to be physically active; those lacking the financial resources cannot freely choose to be involved in regular sporting activities. Unhealthy behaviours, including sedentary lifestyles, are influenced by people's positions within social groups and broad social forces in the general society. The decision about whether to adopt a healthy lifestyle reflects personal attitudes and value preference and thereby includes an aspect of personal choice. But factual personal choice has many preconditions regarding social position and cultural quality of people as well as the access to resources of a full range of choices regarding sporting activities. We can conclude: Healthy lifestyles are patterns of voluntary behaviours based on choices from options available to people according to their life situations. In developed post-industrial countries the members of the upper and middle class by way of 
active lifestyle mostly reflect their value of self identity, emphasising a balanced share of intellectual and physical activities. It is a tendency to evaluate good health as a personal value to be sought and cultivated for one's own benefit, such as experiencing increased vitality and enjoyment of life. Lowerclass individuals, with reference to the nature of their work activities and income, are less optimistic about avoiding poor health and thus are less apt to participate in systematic health promoting activity. Anyway, people in lower socioeconomic positions suffer poorer health and higher disease rates when compared with more privileged social groups.

The phenomenon of physical activity and sport is closely related to urbanisation of sports facilities. In such a context it is useful to describe and analyse the most important milestones in the history of city-planning (urbanisation) in the area of sport facilities. Compared with the development of sport facilities of ancient times the current comparable status seems to be rather negative. Furthermore, it is a paradox that the low quality of urban-planning nowadays is reflected particularly in the suburb areas of Prague, where the public infrastructure (sport facilities included) does not reach a sufficient level. The rapid housing and industrial development especially in these parts of the city has unfortunately overtaken the local development framework, which is resulting in numerous urbanarchitectural and moreover sociological issues. Sport facilities planning, creating, developing and managing should be considered to be one of the strategic points in public administration on both the local and state level (Flemr 2007).

Sport and physical activities in the Czech Republic are also supported in the form of various subsidies. But given the ongoing decentralization policy of the state, numerous problems of given forms of the support of sport and physical activities are not completely solved. So we face some features of the absence of coordinated policy of an effective support of sport damaged by ineffective financing, a high level of political and lobbying decisions. All the relevant institutions on the national, regional and municipal levels should function in coordination across the Czech Republic in their subsidy policies so that financial resources are not dissipated and thus sports and physical education are not negatively impacted by inefficacy. Since 2000, the distribution of subsidies for sport and physical education has been directed to municipalities that invest into development of sport and leisure time infrastructure aiming to grow the local economy, tourism and recreation. The national support of sport is, nowadays, divided into the support of top sports, performance sports and new waves in sports (e.g. sport for everyone - for all), sports for school, which are then on the regional level (and run by the various sport organizations) subsidized from other sources and, moreover, uncoordinated. The correspondence in subsidy policies of all the subsidy levels, i.e. national and regional governments and sport organizations, is thus strongly required. A scheme of priorities in the different levels is proposed so that financially unclear and duplicate resource flow to selected areas is avoided. Due to their multisource financing, sports and physical education are then at the risk of accumulation of resources in certain areas and a lack of resources in others that are not politically supported, but still of high social importance.

Even the preliminary results of the presented research data and pilot studies imply that the individual municipal authorities in the pertinent town areas attach a diametrically different importance to sport and sporting activities. A large difference is already visible in the managing of sport and sporting activities within the organizational structures of the municipal authority. The most critical policy area on physical/sportive activity is the sole fact of sedentary nature of contemporary society: the very high level of prestige of sport and sporting activities in Czech society is incompatible with the very low level of practical regular physical or sporting activities. 


\section{REFERENCES}

Benson, V., Morano, M. (1992). Current Estimates from national Health Interview Survey. Hyattsvills, MD: National Center for H1992,http://www.sendspace.com/file/

Flemr, L. (2007). Podmínky pro aktivní životní styl dětí perspektivou pedagogů tělesné výchovy. Aktuální otázky sociologie sportu. Praha: Karlova univerzita.

Formánková, S. (1998). Některé oblasti longitudinálního nvýzkumu zájmu žáků o pohybovou aktivitu. Celostátní védecká konference s mezinárodní úèastí v oboru kinantropologie. Olomouc: Hanex.

Fořt, P. (2004). Stop dětské obezitě. Praha: Ikar.

Frömel, K. et al. (2004). Physical activity of men and women 18 to 55 years of age in Czech Republic.

Frömel, K., Bauman, A. et al. (2006). Intenzita a objem pohybové aktivity 15-69 leté populace České republiky. Česká kinantropologie. Vol. 10, č. 1, c. 13-27.

Hlúbik, P. et al. (2000). Prevalence of obesity in selected subpopulationsin the Czech Republic. Sborník lékaøský, 1, s. 59-65.

Hobza, V., Cikl, R. (2007). Subvenční politiky ve sportu a tělevýchově v České republice. Česká kinantrolologie. Vol. 2, p. 67-82.

Kovár̆, R. (2002). Tělesná aktivita, tělesná zdatnost a zdraví. Česká kinantropologie, roč. 6, č. 1, s. 49-54.

McElroy, M. (2002). A Social Analysis of Inactivity. Champaign, IL: Human Kinetics.

Rychtecký, A et al. (1995). Effect of Different Physical Activities on Physical and Some Psychological Characteristics of Youngsters aged 11- 14 Years. Kinesiologia Slovenica, 2 (1), p. 44-49..

Rychtecký, A. (2007). Active Lifestyles of Young People - Benefits and Outcomes. In Obesity in Europe. Young People's Physical Activity and Sedentary Lifestyles. Berlin, Oxford: Peter Lang. p. 199- 218.

Ř́hová, M., Skálová L., Komárek, L. (2007). Health Behaviour of Young People. School and Health 21, p. 125139. Brno: Masarykova univerzita a Paido.

Rzewnicky, R. (2003). Health Enhancing Physical activity. Measurement and determinant of daily activity at home, work, travel, and leisure. Leuven: KU Leuven.

Schuster, J. (2007). Přístup společnosti k možnostem redukce nadváhy a obesity intervenèním pohybovým programem. Aktuální otázky sociologie sportu. Praha: UK FTVS.

Sekot, A. (2006). Sociologie sportu. Brno: Masarykova univerzita a Paido.

Sekot, A. (2008). Physical Activity Versus Obesity. Educatio Artis Gymnasticale, roč.3, č. 3, s. 51-72

Sekot, A., Brázdová, Z. (2008). Physical Activity and Nutrition as a Social Factors Influencing the Epidemic of Obesity. Studia Sportiva, roč. 2, č. 1, s. 112-125.

Šeráková, H. (2007). Present views on obesity and overweight in common population of children and adults. School and Health. Brno: Masarykova univerzita a Paido.

Slepička, P., Slepičková, I. (2002). Sport z pohledu české společnosti. Česká kinantropologie, no. 1, p. 7-23.

Slepičková, I., Staněk, M. (2007). The impact of public administration reform on sport policy in Czech Republic. Local Sport in Europe. 4th EASS Conference Proceedings.

Slepičková, I. (2000). Sport Delivery at Municipality Level. Sport, stát, společnost-dodatek (38-46). Praha: UKFTVS.

Slepičková, I. (2001). Public Sector in Sport Delivery - Role of Municipalities and Cities in the European Union and Czech Republic. Sport v České republice na začátku nového tisiciletí (75-78). Proceedings of national conference. Part 2. Praha: UK-FTVS.

Staněk, M., Flemr, L. (2007). The role of local authorities of Czech cities in support of sport: A case study of the capital city of Prague. Local Sport in Europe. EASS 4th Proceedings.

U.S. Department of Health and Human Services. (2000). Understanding and Improving Health. Washington.

WHO (2005). Highlights on health in the Czech Republic. http://euro.who.int/highlights

Vaverka, F. (Ed.). (2007). Movement and Health. Olomouc: Univerzita Palackého. 